\section{White House calls for new materials innovation infrastructure}

\author{
www.whitehouse.gov/administration/eop/ostp \\ http://grants.nih.gov/grants/guide
}

$\mathbf{P}_{\mathrm{b}}$ resident Obama's fiscal year 2012 budget includes $\$ 100$ million for programs to catalyze new activity in computing, software, and data management, and that incorporate new materials into the manufacturing process. This reflects a vision for a new era of materials innovation where advanced materials can be developed, manufactured, and commercialized at significantly less expense and at least twice as fast as is possible today.

This vision was laid out in a white paper released in June by the White House Office of Science and Technology Policy (OSTP) that highlights the need for a new materials innovation infrastructure. The United States would be better equipped to meet its energy, national security, and human welfare goals if new materials could be more rapidly developed and commercialized, according to OSTP. In addition, the country would be more globally competitive in the advanced materials market.

"For the last several decades, technological advancement and economic progress have grown more dependent on advanced materials," said Cyrus Wadia, Assistant Director for Clean Energy and Materials Research and Development at OSTP. "The need and opportunity have aligned in a way that is making possible a new industrial movement where multibillion dollar industries can be created-industries fueled by advanced materials."

Developing a new materials innovation infrastructure will be a multiagency initiative, involving programs in the Department of Energy (DOE), National Institute for Standards and Technology (NIST), National Science Foundation (NSF), and the Department of Defense (DoD). Key elements include an open platform where researchers can share predictive algorithms and computational methods, user-friendly and robust software for modeling materials behavior, and a data management system that facilitates data sharing and searching. These capabilities would augment the experimental tools and techniques related to materials design that have been developed over the last several decades.

In the United States, materials simulation codes are often developed independently, with little collaboration or consistency between laboratories. However, evidence suggests that a more systematic approach could reduce the time and cost of developing new materials.

For example, Japan and Europe have a history of funding collaborative, largescale simulation and coding projects. This has led to open-source tools that enable more efficient data sharing and modeling. Experimental techniques and procedures are often expensive and timeconsuming, and replacing them with accurate simulation tools where possible could dramatically accelerate materials development.

The white paper does not lay out a specific implementation plan for the initiative, but it highlights a number of next steps that would be covered by the $\$ 100$ million funding request:

- The Administration will hold workshops with representatives from government agencies, industries, national laboratories, and universities to discuss infrastructure design, science and engineering challenges, and policy suggestions.

- The DOE's Computational Materials and Chemistry by Design program and NSF's Cyberinfrastructure Framework for 21 st Century Science and Engineering program will oversee the development of high-quality software toolkits.

- DOE and NSF will coordinate the development of next-generation characterization tools that will be used to develop and validate algorithms and software tools.

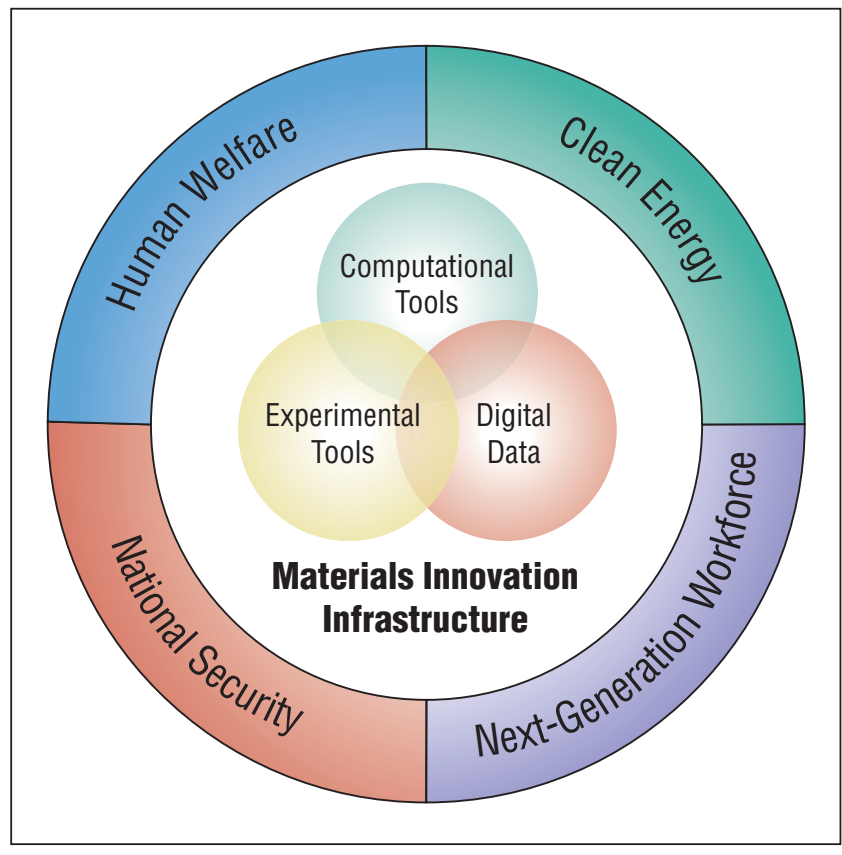

- NIST will lead an Advanced Materials by Design program to develop infrastructure standards, reference databases, and other ways to ensure reliable modeling and simulation.

- NSF and DoD will encourage partnerships among stakeholders to foster collaboration within the community and the large-scale adoption of this new infrastructure, as well as to engage and train a next-generation workforce.

Other efforts within DoD and DOE will focus on 
accelerating the development and adoption of new materials that could help the United States meet national goals, such as increasing energy efficiency and reducing dependence on critical materials with uncertain supply chains.

"We will coordinate activities in various agencies so there is a consistent set of goals and well-defined milestones across the agencies," said Wadia. In addition, he said that a major goal over the next year is to seed a broad set of related activities outside of the federal government, such as industry fellowship programs. Making the vision a reality will require investments from the private sector, academia, professional societies, and the federal government.

"This initiative is an 'all-hands on deck' effort. For this to be successful it will require proactive leadership and creative thinking from the entire materials science community. Our goal is to champion the best ideas while continuing to catalyze and seed new efforts in support of this vision," he said.
The white paper, Materials Genome Initiative for Global Competitiveness, was prepared by an ad hoc group of the Office of Science and Technology Policy's National Science and Technology Council. For more information and to download the paper, visit the Office of Science and Technology Policy's website, www.whitehouse.gov/administration/ eop/ostp.

Kendra Redmond

U.K. proposes Fourth Carbon Budget www.decc.gov.uk www.theccc.org.uk

T

The U.K. Secretary of State for Energy and Climate Change Chris Huhne announced to Parliament in May that the U.S. Government would accept the recommendations of the Committee on Climate Change on the 4th Carbon Budget (2023-2027) in full. The Committee released a proposal to cut carbon emissions by $50 \%$ from 1990 levels by 2025 , putting the United Kingdom on track to meeting the 2050 target (an $80 \%$ reduction in emissions). It will limit emissions over the budget period to $1950 \mathrm{MTCO}_{2} \mathrm{e}$ across all sectors of the economy.

The Committee said that renewable energy should make a major contribution to decarbonizing the U.K. economy over the next decades. Conclusions are set out in the Committee's Renewable Energy Review, released last May. The review highlights a range of renewable energy technologies that could become competitive in the future, including electricity generation from wind and marine, air and ground source heat pumps, and the use of bioenergy for heat generation.

Given sustainability concerns (e.g., the tension between use of land for growth of biofuels, feedstock, and food) a cautious approach to the use of biofuels in surface transport is appropriate, according to the review. Pursuing alternatives to decarbonizing transport is therefore an urgent priority, said the review.

In response to the committee's caution regarding biofuels, Duncan Eggar, chair of the U.K. Research Councils Cross Council Bioenergy Strategic Coordination Group said, "The Research Councils and others invest in research for the development of just such biofuels from inedible plant parts, non-food crops, and agricultural waste-energy sources that should not compete with food production - as well as considering the implications to ecosystem services of new energy crops... Given our research around bioenergy, and the fact that the CCC [Committee on Climate Change] will be exploring biofuels in more depth in the coming months, we would welcome the opportunity to develop a shared understanding with the CCC of the role of advanced biofuels in the future energy mix."

Given significant uncertainties over future developments, the review recommends that the Government should adopt a portfolio approach to technology development. This should cover both renewable generation and other low-carbon technologies.

The review sets out an illustrative scenario where $40 \%$ of electricity would come from renewables, $40 \%$ from nuclear, $15 \%$ from coal and gas with carbon capture and storage, and less than $10 \%$ from unabated gas.

To underpin the portfolio approach, the review argues that the Government should make clear commitments to support less mature renewable technologies such as offshore wind and marine generation through the 2020s. These commitments should then be implemented under new electricity market arrangements.

Chair of the Committee on Climate Change, Lord Adair Turner said, "The focus now should be creating a stable investment climate for renewables, making longer term commitments to support less mature technologies, and putting in place incentives to deliver significantly increased investment in renewable power and heat generation required over the next decade."

Following the release of the Committee's review, Huhne said, "Today's announcement will give investors the certainty they need to invest in clean energy. It puts Britain at the leading edge of a new global industrial transformation as well as making good our determination that this will be the greenest government ever."

Huhne said, "Groundbreaking innovation will play a crucial role in helping Britain to decarbonize its energy supplies by 2027 in the most economical way."

The U.K. Climate Change Act requires that Government publishes a report setting out proposals and policies for meeting the fourth carbon budget "as soon as is reasonably practicable" after setting the new carbon budget in legislation. The Business Plan of the U.K. Department of Energy and Climate Change specifies that Government intends to publish the report in October 2011, which will be done alongside the Carbon Plan. 